How to cite:

Mbuya, T. O., Sinclair, I., Soady, K. A. and Reed, P. A. S. (2017), Application of X-Ray

Microtomography to Evaluate Complex Microstructure and Predict the Lower Bound Fatigue Potential of Cast Al-7(0.7)Si-4Cu-3Ni-Mg Alloys. Adv. Eng. Mater., 1700218.

doi:10.1002/adem.201700218

\title{
Application of X-Ray Microtomography to Evaluate Complex Microstructure and Predict the Lower Bound Fatigue Potential of Cast Al-7(0.7)Si-4Cu-3Ni-Mg Alloys**
}

By Thomas O. Mbuya,* Ian Sinclair, Katherine A. Soady and Philippa A. S. Reed

Dr. T. O. Mbuya

Department of Mechanical and Manufacturing Engineering, University of Nairobi, P.O. Box 30197, 00100 (GPO), Nairobi, Kenya

E-mail:tmbuya@uonbi.ac.ke

Dr. T. O. Mbuya, Prof. I. Sinclair, Dr. K. A. Soady, Prof. P. A. S. Reed

Engineering Materials Group, Faculty of Engineering and the Environment,

Highfield, University of Southampton, Southampton SO17 1BJ, UK.

[**] The authors acknowledge Dr. Andrew Moffat for the two SEM images used in this work. The first author also acknowledges the University of Southampton and the University of Nairobi for their financial support that made it possible for this work to be carried out.

The 3D architecture of intermetallics and porosity in two multicomponent cast Al-7(0.7)Si$4 \mathrm{Cu}-3 \mathrm{Ni}-\mathrm{Mg}$ alloys is characterised using conventional microscopy and X-ray microtomography. The two alloys are found to contain intermetallic phases such as $\mathrm{Al}_{3} \mathrm{Ni}$, $\mathrm{Al}_{3}(\mathrm{NiCu})_{2}, \mathrm{Al}{ }_{9} \mathrm{FeNi}$ and $\mathrm{Al}_{5} \mathrm{Cu}_{2} \mathrm{Mg}_{8} \mathrm{Si}_{6}$ that have complex networked morphology in $3 \mathrm{D}$. The results also show that HIPping does not significantly affect the volume fraction, size and shape distribution of the intermetallic phases in both alloys. A novel technique similar to serial sectioning that circumvents quantification difficulties associated with interconnected particles is used to quantify the intermetallics. The largest particle size distribution is then correlated to fatigue performance using extreme value analysis to predict the maximum particle size in a sample of $S$ - $N$ fatigue specimens and subsequently, the lower bound fatigue life. The predictions are found to correlate well with fatigue data. The effect of HIPping on porosity characteristics is also characterised. Large pore clusters with complex morphology are observed in the unHIPped versions of both alloys but more significant in the low Si (Al0.7Si-4Cu-3Ni-Mg) alloy. However, these are significantly reduced after HIPping. The differences between $2 D$ and $3 D$ pore morphology and size distribution is discussed in terms of the appropriate pore size parameter for fatigue life prediction.

KEYWORDS: Cast aluminium; X-ray microtomography; Microstructure; Fatigue; Extreme Value Analysis

\section{Introduction}

The fatigue performance of aluminium castings is controlled by their structure, which includes casting defects and microstructural constituents. ${ }^{[1,2]}$ While these alloys have found widespread application in transport vehicle systems such as in several automotive power-train components (e.g. engine pistons, cylinder heads and engine blocks), their fatigue performance 
is significantly impaired by porosity and other defects (e.g. oxides) that are inherent in castings. ${ }^{[2]}$ It is now well known that these defects, especially porosity, are potent fatigue crack initiators and result in a significant reduction in fatigue life depending on their size and spatial distribution within the casting. ${ }^{[2,3]}$ Defect levels can, however, be minimised through casting design optimisation and careful molten metal treatment. ${ }^{[2,4]}$ Moreover, porosity can also be removed or reduced by hot isostatic pressing (HIPping) to levels that make it less potent in fatigue crack initiation ${ }^{[5]}$ and hence improved fatigue life (typically by an order of magnitude). ${ }^{[6]}$ HIPping is however not effective for surface connected porosity ${ }^{[7]}$ and it does not seem to affect oxides which begin to play a more significant role in fatigue cracking. ${ }^{[8]}$ It is when these defects are minimised that other microstructure features such as Si particles and intermetallic compounds begin to dominate fatigue crack initiation. ${ }^{[9]}$

Automotive engine pistons are typically produced from heavily alloyed Al-Si alloys with highly interconnected complex microstructure. ${ }^{[10]}$ Low Si $(6.9$ and $0.67 \mathrm{wt} . \%)$ model piston alloys (see Table 1) have also been developed as alternatives to avoid fatigue crack initiation from primary $\mathrm{Si}$ as often observed in the conventional near eutectic alloys. ${ }^{[11]}$ However, these low Si alloys are reported to contain higher levels of porosity that deteriorate fatigue performance. ${ }^{[9,11]}$ In this study, porosity in these alloys has been reduced by HIPping to levels that make it less potent in fatigue crack initiation. However, the microstructure of these alloys must be well understood in order to optimise and accurately predict their fatigue performance.

Conventional methods for microstructure characterisation usually involve two-dimensional (2D) image analysis of sectioned and polished specimens using optical microscopy (OM) or scanning electron microscopy (SEM). However, most microstructures are three-dimensional (3D) in nature and their geometric attributes in the bulk (e.g., amount, size and shape distribution and their spatial arrangement) significantly influence the mechanical response of materials. ${ }^{[12]}$ The need for $3 \mathrm{D}$ characterisation has therefore long been recognised. ${ }^{[13]}$ Although it is possible to analytically obtain some 3D feature information from 2D image analysis (e.g. using the Saltykov methods ${ }^{[14]}$ ), this is not possible for complex microstructures such as those in cast aluminium piston alloys in Table 1. As such, imaging techniques such as serial sectioning or X-ray microtomography ${ }^{[13,15]}$ are required for a better 3D microstructure and defect characterisation. Serial sectioning has been used for at least four decades with increasing efficiency and accuracy with the introduction of montage serial sectioning ${ }^{[16]}$ and automation techniques. ${ }^{[17]}$ The method is however destructive as well as labour intensive and time consuming when carried out manually. 3D X-ray microtomography is therefore an invaluable approach in the characterisation of materials especially using synchrotron radiation sources. It has for example been used to characterise porosity and its interaction with fatigue crack growth in cast aluminium alloys. ${ }^{[18]}$ It has also been used to characterise microstructure features such as Si and intermetallic phases ${ }^{[19]}$ and the growth behaviour of both short ${ }^{[20]}$ and long fatigue cracks. ${ }^{[21]}$

In this paper, the highly complex morphology and 3D interconnectivity of intermetallics and porosity in both the HIPped and unHIPped versions of these alloys is examined using synchrotron radiation computed tomography (SRCT) and advanced image analysis tools. A novel technique is employed to quantify intermetallic particle size distribution, which is then correlated to fatigue performance using extreme value analysis (EVA).

\section{Materials and Experimental Method}

The alloys under investigation (Table 1) were supplied as unfinished pistons in the HIPped and unHIPped (not HIPped) conditions. The HIPped pistons were supplied after being subjected to a HIPping and heat treatment procedure involving holding at $490^{\circ} \mathrm{C}$ and $100 \mathrm{MPa}$ 
for $4 \mathrm{~h}$, followed by solution treatment at $480^{\circ} \mathrm{C}$ for $2 \mathrm{~h}$, water quench and finally ageing for 8 $\mathrm{h}$ at $230^{\circ} \mathrm{C}$. The unHIPped pistons were supplied in the T5 temper (i.e. aged at $230^{\circ} \mathrm{C}$ for $8 \mathrm{~h}$ ). Specimens for microstructure analysis and mechanical testing were then taken from the piston crowns and further overaged at $260^{\circ} \mathrm{C}$ for $100 \mathrm{~h}$ to simulate changes to microstructure after prolonged exposure to piston in-service temperatures.

SRCT imaging was carried out on $2 \times 2 \times 10 \mathrm{~mm}^{3}$ match stick samples that were sectioned from the HIPped and unHIPped piston crowns in the direction parallel to the crown surface. The samples were scanned at the European Synchrotron Radiation Facility (ESRF) ID19 beamline using an X-ray beam energy of $20 \mathrm{keV}$ to obtain reconstructed volumes with an isotropic voxel resolution of $1.4 \mu \mathrm{m}$. The various geometrical attributes of pores and intermetallic particles in the reconstructed SRCT volumes were analysed using VGStudio Max and ImageJ.

Table 1 Compositions (in wt. \%) of the model cast aluminium piston alloys

\begin{tabular}{llllllllllll}
\hline Alloy & $\mathrm{Si}$ & $\mathrm{Cu}$ & $\mathrm{Ni}$ & $\mathrm{Mg}$ & $\mathrm{Fe}$ & $\mathrm{Mn}$ & $\mathrm{Ti}$ & $\mathrm{Zr}$ & $\mathrm{V}$ & $\mathrm{P}$ & $\mathrm{Sr}$ \\
\hline Al7Si-Sr & 6.90 & 3.89 & 3.00 & 0.62 & 0.22 & 0.03 & 0.01 & 0.05 & 0.04 & 0.005 & 0.015 \\
Al0.7Si & 0.67 & 3.91 & 2.99 & 0.80 & 0.21 & 0.05 & 0.01 & 0.01 & 0.01 & 0.005 & 0 \\
\hline
\end{tabular}

Bend bar S-N specimens of square cross section measuring 6x6x50 mm were also sectioned from the piston crowns of the HIPped Al7Si-Sr and Al0.7Si alloys and aged at $260^{\circ} \mathrm{C}$ for 100 $\mathrm{h}$. Prior to testing, the top surface of each specimen was polished to $\sim 0.05 \mu \mathrm{m}$ finish and the edges rounded off (to $\sim 0.5 \mathrm{~mm}$ in radius) to reduce chances of them acting as fatigue crack initiation sites. Room temperature $\mathrm{S}-\mathrm{N}$ fatigue tests were then performed at different stress (strain) amplitudes on a $50 \mathrm{kN}$ Instron 8502 fatigue testing machine using 4 point bend loading geometry with a span of $15 \mathrm{~mm}$, stress ratio (R) of 0.1 and a frequency of $50 \mathrm{~Hz}$. The origins of fatal fatigue cracks were investigated by analysing the fracture surfaces using an SEM fitted with an energy dispersive X-ray (EDX) unit, which was used to analyse the phases. All SEM images presented in this paper were taken using backscattered electron mode at an accelerating voltage of $15 \mathrm{kV}$.

For all specimens tested, the maximum near-surface tensile stresses were above the $0.2 \%$ proof stress $\left(\sigma_{0.2}\right)$ of the material (i.e., $\sim 130 \mathrm{MPa}$ for HIPped Al0.7Si and $\sim 110 \mathrm{MPa}$ for HIPped Al7Si-Sr ${ }^{[9]}$ ). While the bulk of the specimen remained elastic, the near-surface tensile region of the specimens was plastically deformed. Finite element (FE) calculations were therefore carried out in ABAQUS to determine the stress and strain distributions at the region of maximum bending moment. The FE calculations were based on monotonic uniaxial tensile stress-strain data used to inform the material model, assuming isotropic hardening behaviour, applied to the appropriate bend bar geometry. The models were meshed using C3D20R elements at a range of mesh sizes to ensure that results were independent of mesh density.

\section{Results and Analysis}

\subsection{D Microstructure Characterisation (Optical and SEM)}

The typical optical microstructure of HIPped and unHIPped A10.7Si alloys is shown in Figure 1. Figure 1a shows that the unHIPped A10.7Si alloy microstructure mainly comprises the $\alpha$-Al matrix and a network of intermetallic compounds. The secondary dendrite arm spacing (SDAS) was measured using the line intercept method and found to be $\sim 37.3 \pm 10 \mu \mathrm{m}$ and the volume fraction $\left(\mathrm{V}_{\mathrm{f}}\right)$ of the intermetallics was measured and found to be $\sim 12.1 \pm 2.2 \%{ }^{[22]}$ Figure 1a also shows an intermetallic cluster in the unHIPped microstructure. These intermetallic clusters were frequently observed in this alloy and the volume fraction $\left(\mathrm{V}_{\mathrm{f}}\right)$ of 
the intermetallics at the cluster regions was measured and found to be $\sim 21.5 \pm 2.1 \%$. This clustering of intermetallics was also observed in the HIPped version of the alloy as shown in Figure $1 \mathrm{~b}$. The SDAS of the HIPped alloy $(\sim 37.8 \pm 4.1 \mu \mathrm{m})$ was found to be comparable to that of the unHIPped alloy as expected because this is a function of cooling rate. The SEM micrographs in Figures $1 \mathrm{c}$ and $1 \mathrm{~d}$ indicate some of the phases found in this alloy such as $\mathrm{Al}_{3} \mathrm{Ni}$ and $\mathrm{Al}_{3}(\mathrm{NiCu})_{2}$. Other phases that were identified by EDX but not shown here are $\mathrm{Al}_{9} \mathrm{FeNi}, \mathrm{Al}_{5} \mathrm{Cu}_{2} \mathrm{Mg}_{8} \mathrm{Si}_{6}$ and $\mathrm{Al}_{2} \mathrm{Cu}$ for both the HIPped and unHIPped alloy. Unlike most multicomponent piston alloys, which are mainly near eutectic Al-Si alloys, this alloy is not a cast $\mathrm{Al}-\mathrm{Si}$ alloy because its $\mathrm{Si}$ content $(0.67 \mathrm{wt} . \% \mathrm{Si})$ is well below the maximum equilibrium solid solubility of $\mathrm{Si}$ in $\mathrm{Al}$ (i.e., $1.65 \mathrm{wt} . \% \mathrm{Si}^{[23]}$ ). Cast $\mathrm{Al}-\mathrm{Si}$ alloys typically contain $\mathrm{Si}$ contents above $5 \mathrm{wt} . \%$. The alloy is therefore not expected to contain Si particles within its dendritic microstructure although non-equilibrium Scheil thermodynamic simulations predict formation of trace amounts (0.074 wt. of Si particles) ${ }^{[24]}$ The volume fraction of the intermetallics in the HIPped alloy reduced slightly to $\sim 9.7 \pm 1.6 \%$ possibly due to partial dissolution of $\mathrm{Al}_{5} \mathrm{Cu}_{2} \mathrm{Mg}_{8} \mathrm{Si}_{6}$ and $\mathrm{Al}_{2} \mathrm{Cu}$ phases during HIPping and solution treatment. ${ }^{[24]}$

The presence of oxide particles was also observed in the HIPped alloy as shown in Figure 1c. The presence of oxides was confirmed via EDX whose results show the presence of oxygen and sometimes magnesium. Figure 1e presents an interesting secondary fatigue crack found on a fatigue tested specimen that suggests the presence of crack-like oxide films (possibly bifilms). Thin crack-like oxide defects are frequently observed in Al castings (e.g., see Fuoco et $\left.a l .{ }^{[25]}\right)$. However, it can also be argued that some of these cracks may be due to failed particles just underneath the surface or possibly thin crack-like interdendritic pores that were collapsed but not completely welded during HIPping. Recent observations ${ }^{[26]}$ have shown that pores co-existing with oxides may not completely weld closed as opposed to oxide free pores that effectively heal during HIPping. The co-existence of pores with oxide films may explain why these oxides are not easily discerned in the unHIPped alloy. The proposition that the crack in Figure 1e is a consequence of an existing crack-like oxide film could provide an explanation for some of the out-of-plane fatigue cracks observed in the fracture surfaces of this alloy, as shown in Figure 1f. Figure 1f shows a crack that appears to extend from an oxide particle although it does not seem to be connected to any of the cracks in the oxide. Whereas this may truly be a typical bifurcation of the main crack due to particle failure (underneath the surface), its nature does pose the question whether it is not really an oxide film. 

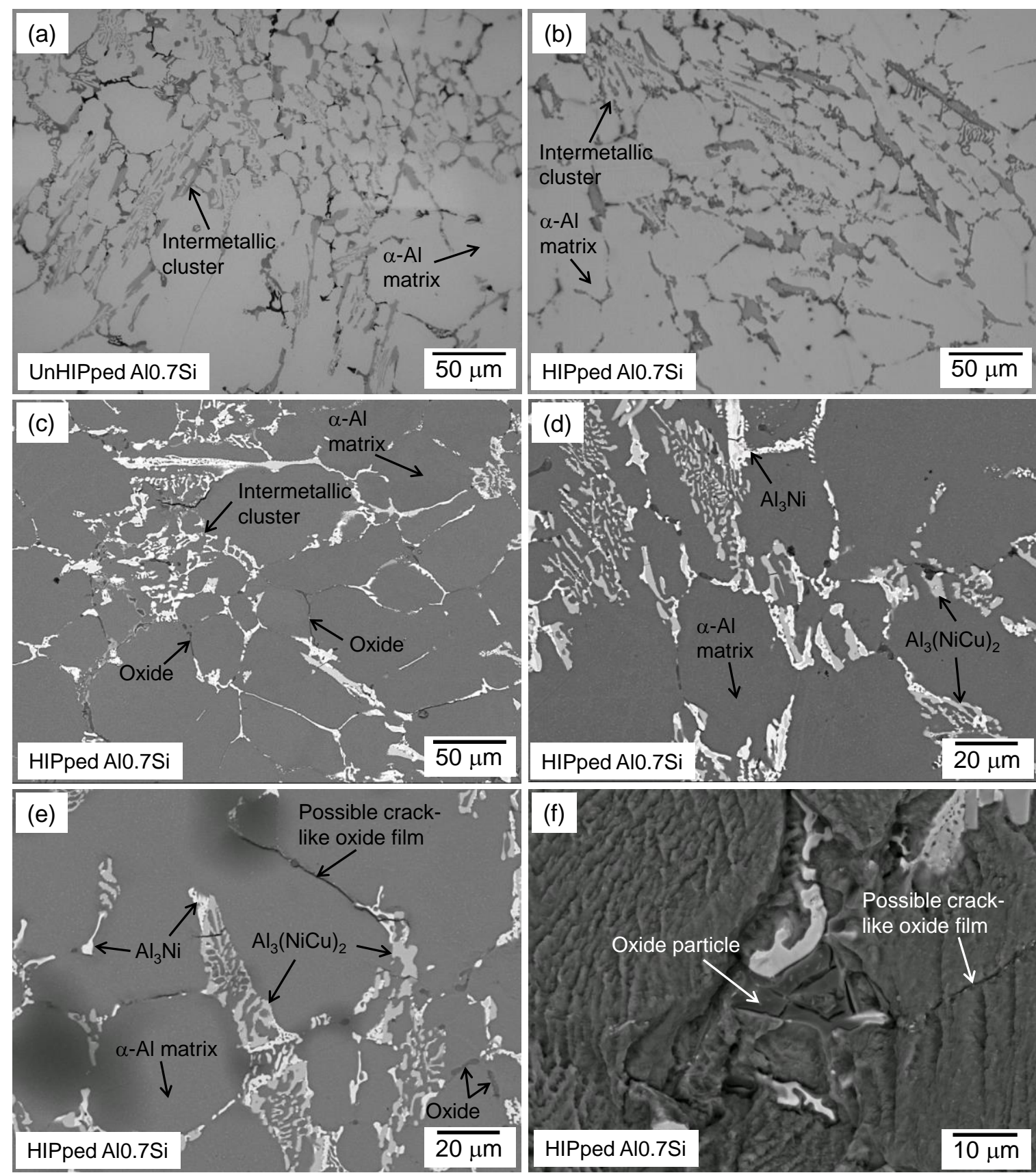

Figure 1. Optical micrographs showing intermetallic clusters of (a) unHIPped A10.7Si and (b) HIPped Al0.7Si alloys. The SEM micrograph in (c) shows the intermetallics in the HIPped A10.7Si alloy in which an intermetallic cluster and oxides are identified. Some of the intemetallic phases observed in this alloy are identified in the higher magnification SEM image in (d). (e) shows an SEM micrograph taken from an S-N sample of the HIPped Al0.7Si alloy showing fatigue cracks that may have been a consequence of pre-existing crack-like oxide films (possibly bifilms). (f) SEM fractograph at the crack propagation region showing a possible crack-like oxide film extending from an oxide particle.

Figure $2 \mathrm{a}$ and $2 \mathrm{~b}$ respectively show the typical microstructure of the unHIPped and HIPped Al7Si-Sr alloys with an average SDAS of $\sim 28.5 \mu \mathrm{m}$. The SEM micrographs shown in Figures $2 \mathrm{c}$ and $2 \mathrm{~d}$ provide a better illustration of the intermetallics structure observed in the HIPped alloy. These figures show the presence of various types of intermetallics as well as Si particles located at the eutectic regions. It should be noted that eutectic regions are locally heterogeneous in the sense that some regions exhibit dense clusters of Si (and intermetallic) 
particles while others are small in size and therefore contain fewer particles. Some of the intermetallic compounds in the HIPped alloy are identified in the SEM image shown in Figure 2d. These include $\mathrm{Al}_{3}(\mathrm{NiCu})_{2}, \mathrm{Al}_{9} \mathrm{FeNi}$ and $\lambda-\mathrm{Al}_{5} \mathrm{Cu}_{2} \mathrm{Mg}_{8} \mathrm{Si}_{6}$. This is consistent with observations by Chen ${ }^{[24]}$ who also observed trace amounts of $\mathrm{Al}_{7} \mathrm{Cu}_{4} \mathrm{Ni}, \mathrm{Al}_{3} \mathrm{Ni}$ and $\alpha-$ $\mathrm{AlFeMnSi}$ phases in the unHIPped version of this alloy. It is noteworthy that oxide particles were not observed in the microstructure of this alloy. This seems to suggest that the higher level of Si reduces the propensity for oxide formation in this alloy. However, also observed in Figure $2 \mathrm{~d}$ is a phase indicated as $\mathrm{Al}_{3}(\mathrm{NiCuFeSi})_{2}$ that appears to comprise many tiny particles clustered together. This phase was often seen attached to $\mathrm{Al}_{9} \mathrm{FeNi}$ particles and has a chemical composition close to that of $\mathrm{Al}_{3}(\mathrm{NiCu})_{2}$ except for the higher $\mathrm{Si}$ and $\mathrm{Fe}$ contents it contains as compared to those commonly found in the $\mathrm{Al}_{3}(\mathrm{NiCu})_{2}$ phase. Furthermore, another phase with a stoichiometry that is close to $\mathrm{Al}_{2} \mathrm{Ni}(\mathrm{CuSiZrFeMg})$ was also observed in this alloy and found to contribute to fatigue crack initiation as reported elsewhere. ${ }^{[27]}$ This phase was first observed by Edwards et al. ${ }^{[28]}$ in an AE160 commercial piston alloy and contains $\mathrm{Zr}$ at significantly high levels.

It was observed that HIPping did not affect the volume fraction of hard particles (Si and intermetallics) in the Al7Si-Sr alloy which was found to be $19.5 \pm 2.4 \%$ for the unHIPped alloy and $19.4 \pm 2.0 \%$ for HIPped alloy. A similar value of $19.4 \pm 3 \%$ was obtained for the HIPped alloy from the image analysis of optical and backscattered SEM images using ImageJ. The clear contrast between Si particles and intermetallics in backscattered SEM images made it possible to obtain the volume fraction of intermetallics alone as $10.8 \pm 2.8 \%$.
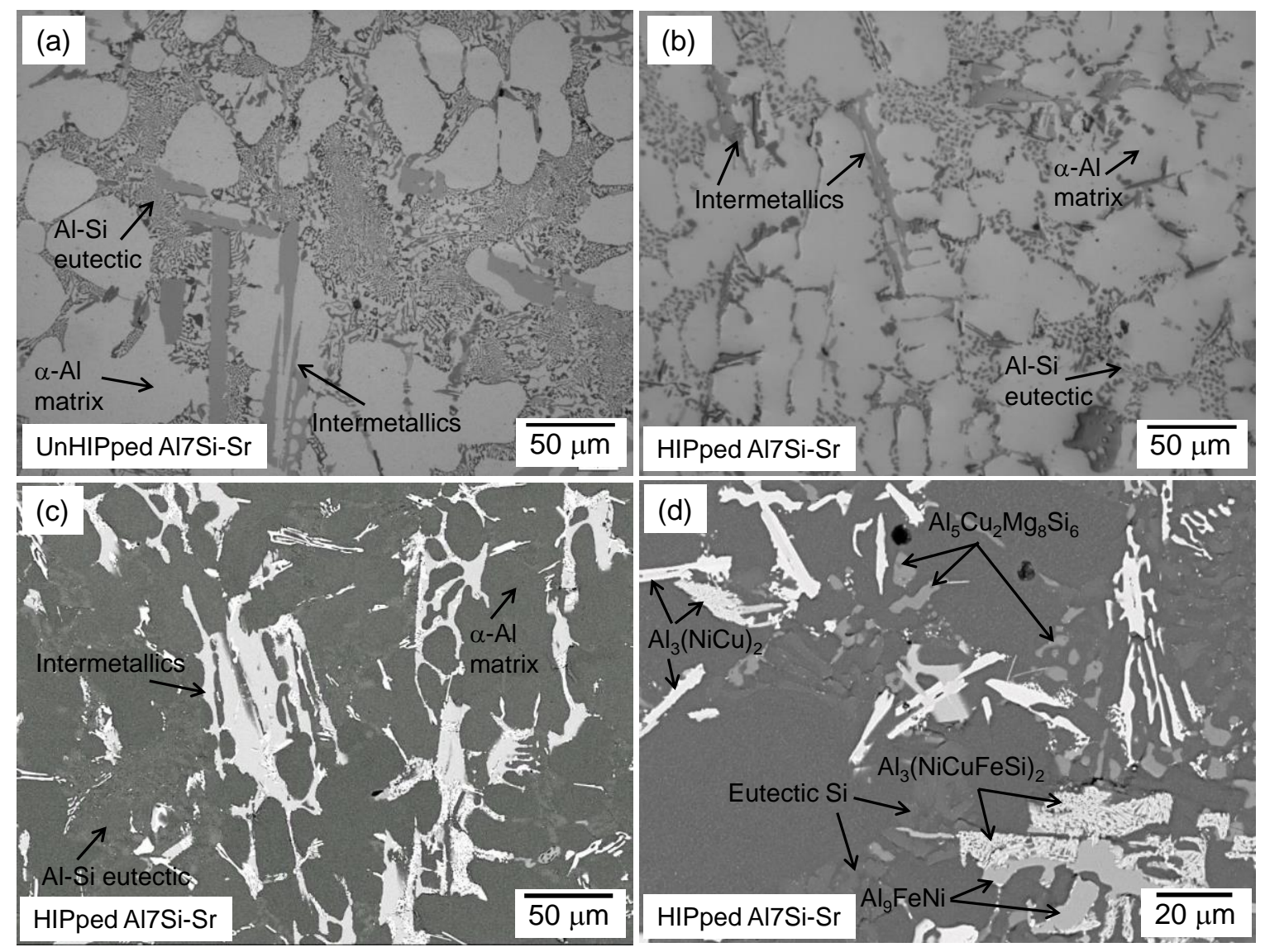

Figure 2. Optical micrographs showing eutectic Si and intermetallic clusters of (a) unHIPped Al0.7Si and (b) HIPped Al7Si-Sr alloys. The SEM micrograph in (c) shows the intermetallics in the HIPped Al7Si-Sr alloy in which the intermetallics are more clearly depicted. Some of 
the intemetallic compounds observed in this alloy are identified in the higher magnification SEM image in $(\mathrm{d})$.

\subsection{D SRCT Intermetallic Characterization and Extreme Value Analysis}

Figure 3 shows SRCT images that depict the complex 3D network of the intermetallic structure in the unHIPped and HIPped versions of A10.7Si and Al7Si-Sr alloys. The large intermetallic clusters observed in the A10.7Si alloy can be seen clearly in Figure $3 \mathrm{a}$ and $3 \mathrm{~b}$ for both the unHIPped and HIPped alloys. A large intermetallic cluster is also observed in the HIPped version of Al7Si-Sr alloy (Fig. 3d). In contrast to A10.7Si alloy, these large clusters of intermetallics were not frequently observed in optical and SEM micrographs of the Al7Si-Sr alloy in both unHIPped and HIPped conditions. This may be attributed to the high Si content in this alloy and the presence of $\mathrm{Sr}$ that have been reported to fundamentally affect the evolution of intermetallics in other cast Al-Si alloys during solidification. ${ }^{[29,30]}$ Note that there was no sufficient contrast to image Si particles in the Al7Si-Sr alloy although there was clear contrast between intermetallic structures and the aluminium matrix (including the eutectic silicon). 

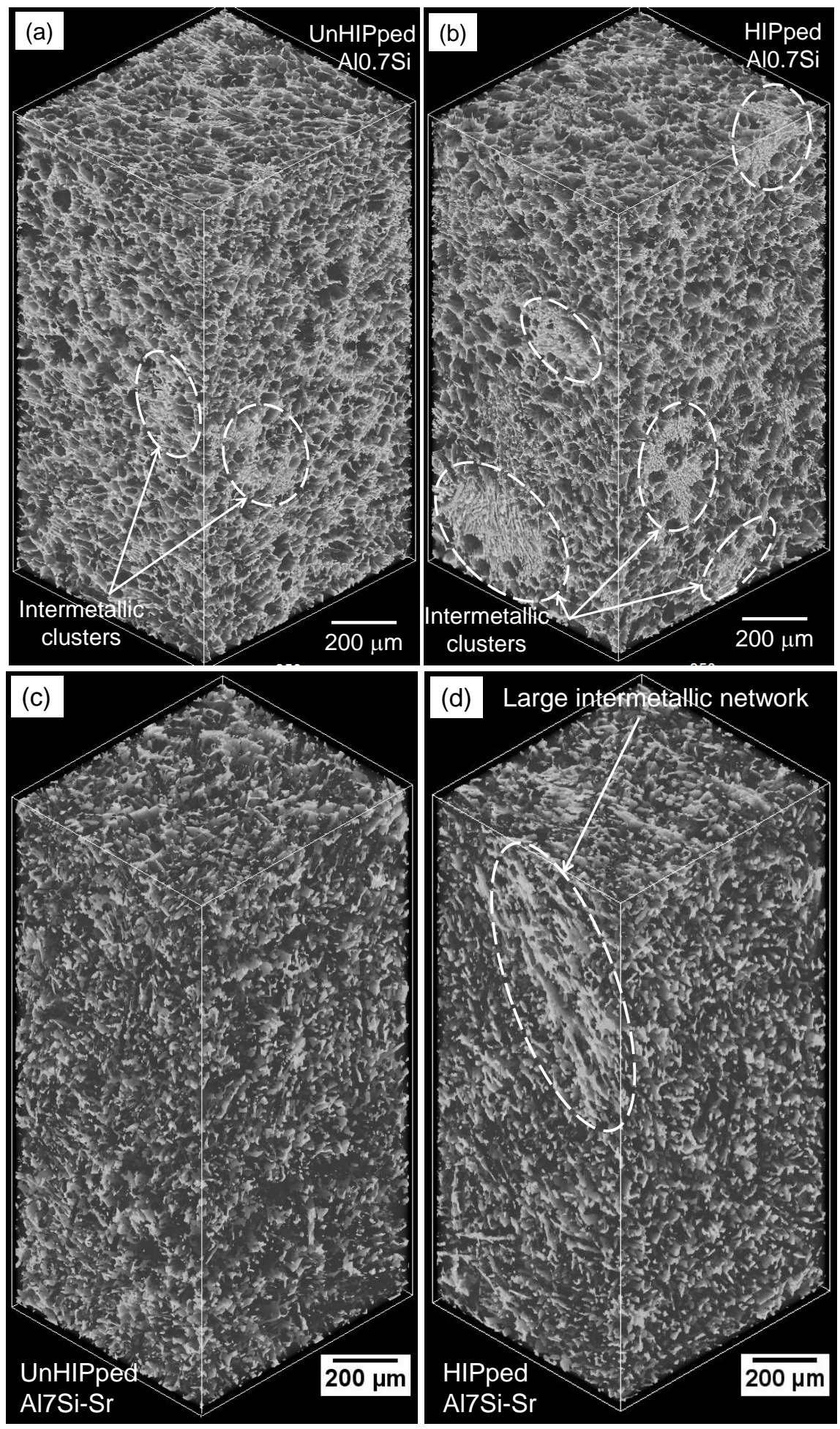

Figure 3. SRCT images showing the complex 3D network of the intermetallic structures in (a) unHIPped Al0.7Si, (b) HIPped Al0.7Si, (c) unHIPped AlSi-Sr and (b) HIPped AlSi-Sr.

The high interconnectivity of the intermetallic particles in 3D makes quantitative characterization of their various geometric attributes a challenging task because segmentation of individual phases is not practical. Some particles are interconnected in such a way that they form a semblance of a cellular network that traverses through the whole volume along with other discrete particles. Such a network would therefore be identified as one large particle during segmentation and the rest as several small particles. This kind of measurement does not provide useful information that can be correlated with mechanical performance.

Micromechanisms of fatigue crack initiation and short crack growth in metallic materials are 
localised events. Moreover, fatigue cracking at particles is planar irrespective of its shape complexity. Indeed, it is on this basis that the parameter $\sqrt{\text { area }}$ has been successful in correlating defect size with fatigue performance. ${ }^{31}$ The parameter $\sqrt{\text { area }}$ is obtained by projecting the defect (e.g. pore, particles) onto the plane perpendicular to the maximum tensile stress.

Moreover, the 2D quantitative analysis of SEM images reported in Mbuya et al. ${ }^{[9]}$ ] for these alloys provide a good first estimate of their geometrical attributes that can be readily correlated with mechanical properties. Note that significant interconnectivity is retained even on $2 \mathrm{D}$ images as shown in Figure $1 \mathrm{a}$ and $1 \mathrm{~b}$, which to some extent serves as measure of the interconnectivity in 3D but yet allows more reasonable quantitative measurements to be carried out. This observation provided an avenue for quantifying the intermetallic particles in the 3D SRCT images. Instead of quantifying the 3D geometry of each phase, a 2D analysis of phases in each SRCT slice was carried out. This method makes it possible to obtain the largest cross-sectional area of each particle in the volume (as viewed in a given direction) since the particle is sliced and measured several times (serially) through its volume along a given direction. It is akin to serial sectioning but without reconstructing the slices into a 3D volume. Furthermore, it is possible to cover a much larger area in each slice (up to $\sim 4 \mathrm{~mm}^{2}$ in this case) which is not possible with 2D optical or SEM images unless a montage of several images is produced. This quantitative analysis can be applied in extreme value analysis to predict the lower bound fatigue performance of these alloys. However, it should be noted that any given particle will be measured several times; as often as the number of slices cutting through it. This should therefore be kept in mind during data interpretation.

Figure 4 shows the results of such analysis on limited SRCT volumes $\left(\sim 0.08 \mathrm{~mm}^{3}\right)$ for purposes of evaluating the effect of HIPping for both alloys. It is clear that HIPping does not significantly affect the overall geometrical relationship between morphology (i.e. circularity) and particle size. For comparison purposes, the particle size is presented as particle area (Fig. $4 \mathrm{a}$ and $\mathrm{b}$ ) and the maximum Feret dimension ( $\mathrm{L}_{\max }$ ) (Fig. $4 \mathrm{c}$ and $\mathrm{d}$ ) for the unHIPped and HIPped Al0.7Si alloys. Note that circularity is a measure of how close the shape is to a circle - a circularity value of unity indicates a perfect circle and as it approaches zero, it indicates an increasingly elongated shape. The maximum Feret dimension is the diagonal of the bounding rectangle of the section area of the defect or particle.

It can be seen in Figure 4 that when using Lmax, there is no major difference in the particle size and shape distribution between the HIPped and unHIPped Al0.7Si alloys. However, when using particle area, a significant number of the upper tail of the particles in the HIPped A10.7Si alloy are larger than the largest particle observed in the unHIPped alloy. It can also be seen that for both alloys, the circularity is between $\sim 0.2$ to 1 for the smallest particles of less than $\sim 20 \mu \mathrm{m}$. Large particles have circularity values that are much lower than $\sim 0.2$. This confirms the irregular morphology expected of larger particles which are generally interconnected and highly convoluted as already discussed. 

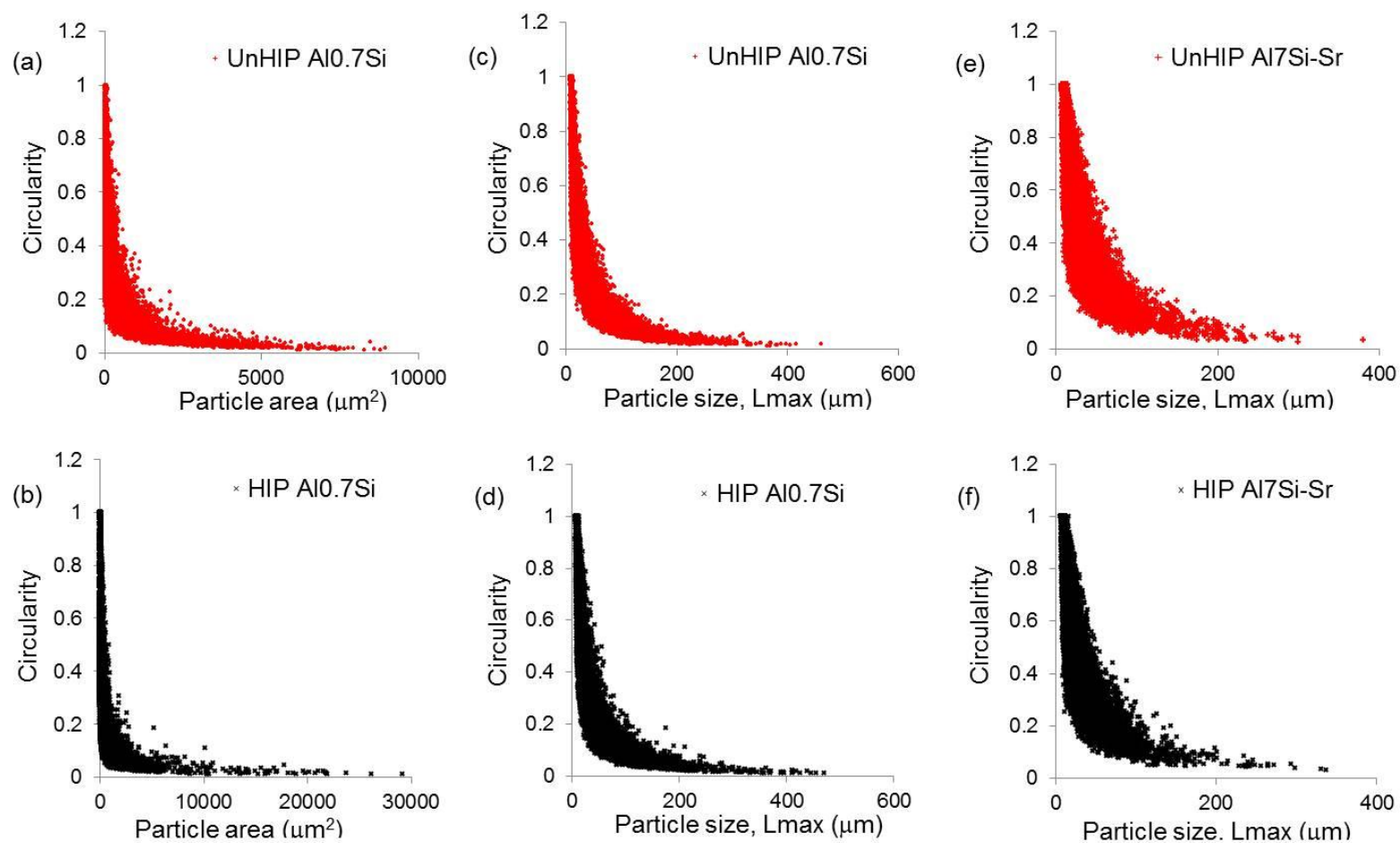

Figure 4. shows a comparison of intermetallic particle size - circularity relationship in unHIPped and HIPped A10.7Si (a to d) and Al7Si-Sr alloys (e and f). The particle size is presented as area (a and $b$ ) and maximum Feret dimension $\left(\mathrm{L}_{\max }\right)$ (c and d) for the unHIPped and HIPped Al0.7Si alloy.

The lower bound fatigue life can be predicted from the size of the largest defect (i.e. pores or particles) in the sample, which is often predicted from the upper tail of the defect distribution by extrapolation using extreme-value analysis. ${ }^{[31-34]}$ The sizes of the largest defects have been shown to follow one of the extreme-value distribution functions (i.e., Gumbel, Frechet or Weibull). ${ }^{[35,36]}$ We have previously reported ${ }^{[9]}$ that fatigue cracks for the HIPped Al0.7Si and A17Si-Sr alloys originate from intermetallic particles which mostly lie at the upper tail of the particle size population. It should therefore be expected that the largest particles measured from the SRCT volumes will play a significant role in determining the lower bound fatigue performance of these alloys. To provide useful information for EVA, the SRCT volume for each alloy was divided into smaller equal volumes for a systematic control volume $\left(\mathrm{V}_{\mathrm{o}}\right)$ particle analysis as indicated in Table 2. Particle sizes in each of these volumes were then measured using the same procedure as previously discussed. The sizes of the largest particles in each of the volumes for each alloy were then fitted to Gumbel distribution plots as shown in Figure 5a. The Gumbel distribution function is one of the extreme value distributions which is often used for EVA analysis of defects and inclusions in castings and its cumulative probability function is given by

$$
P(x)=\exp \left(-\exp \left(\frac{x-\lambda_{\mathrm{g}}}{\delta}\right)\right)
$$

Where,

$x=$ Particle size (particle area in this case)

$\lambda_{\mathrm{g}}=$ Location

$\delta=$ Scale parameter

Table 2. The number and size of control volumes $\left(\mathrm{V}_{\mathrm{o}}\right)$ used in extreme value analysis

\begin{tabular}{lll}
\hline Alloy & $\begin{array}{l}\text { Number of } \\
\text { Volumes, } \mathrm{V}_{\mathrm{o}}\end{array}$ & $\begin{array}{l}\text { Size of each } \\
\text { volume }\left(\mu^{3}\right)\end{array}$ \\
\hline HIPped A10.7Si & 16 & 53425680
\end{tabular}



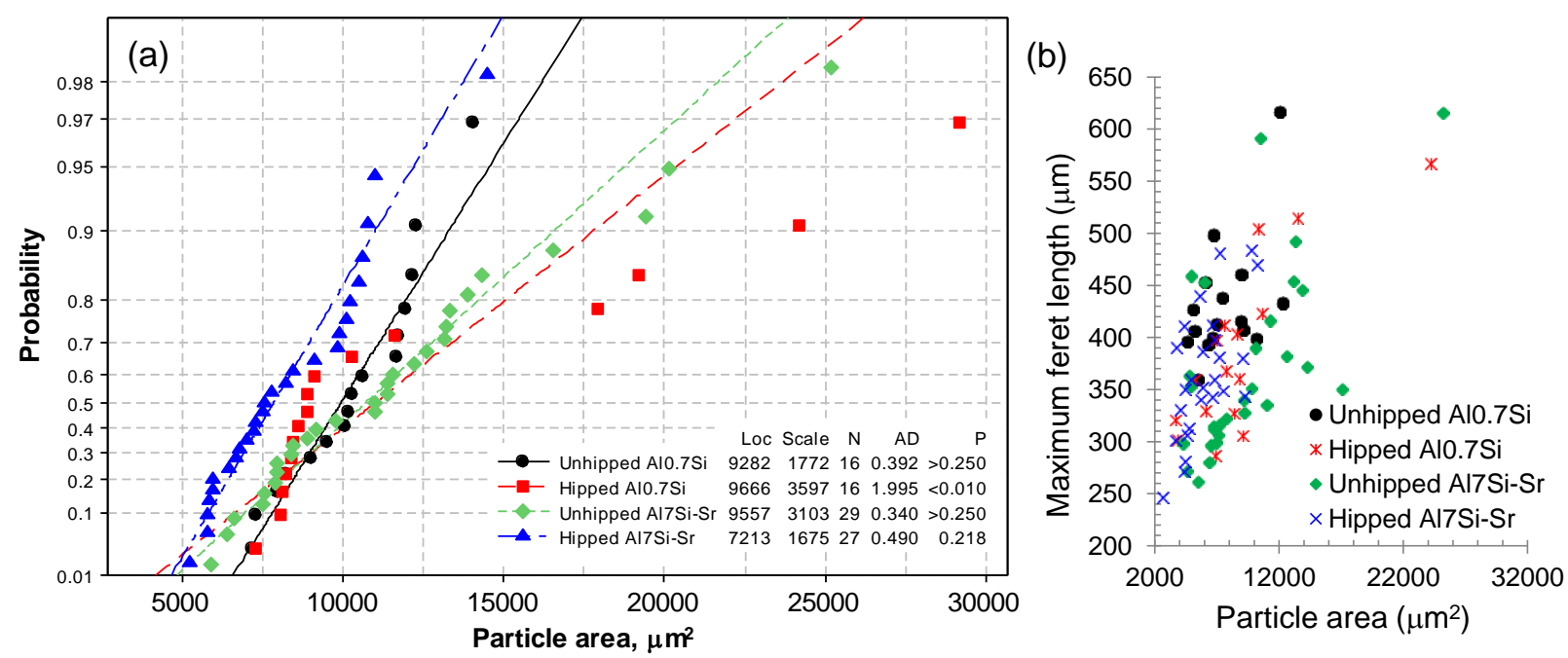

Figure 5. (a) Gumbel probability plots for the largest particles in selected volumes of unHIPped and HIPped A10.7Si and A17Si-Sr alloys. (b) Comparison of the maximum ferret dimension of the largest particles with the corresponding particle areas.

Figure 5a shows that the Gumbel distribution function provides excellent fit for the largest particle sizes for all alloys except the HIPped A10.7Si. This is based on the Anderson-Darling goodness of fit test statistic as described Tiryakioglu. ${ }^{[35]}$ The lower the value of AD, the higher the confidence that the data follows the hypothesized distribution and the hypothesis is rejected when the $\mathrm{p}$ value is typically less than 0.05 .

The largest particle size distribution for the HIPped A10.7Si alloy indicates two distinct populations, which is most likely attributable to the presence of large clusters observed in the SRCT volumes of this alloy (see Figure 3b). An examination of the individual SRCT volumes in the HIPped A10.7Si alloy confirmed that most of the largest particles were from volumes with relatively larger clusters. Nevertheless, the estimated Gumbel distribution location $\left(\lambda_{\mathrm{g}}\right)$ and scale $(\delta)$ parameters can be used as direct inputs into an extreme value analysis to estimate the expected size of the largest particle that can be found in a larger component of any known volume. This can then in turn be used as input into a suitable fatigue life prediction model to predict the lower bound fatigue performance of the component.

Figure $5 b$ presents $\mathrm{L}_{\max }$ plotted against the corresponding particle area for these largest particles for all the alloys. It can be seen that there is no clear trend between $\mathrm{L}_{\max }$ and the area of the particles although there is a subtle increase in $\mathrm{L}_{\max }$ with area. This is attributable to the complex morphology of these particles and is in line with the observation in Figure 4 that larger particles have low circularity. The more significant observation however is that these particles have areas above $2000 \mu \mathrm{m}^{2}$. If this is compared with Figure 6a it is noted that the lower bound fatigue lives for the HIPped Al7Si-Sr alloy correspond to crack initiating particles of areas ranging from $\sim 800 \mu \mathrm{m}^{2}$ to $\sim 4000 \mu \mathrm{m}^{2}$. It worth noting that Figure 6a shows that thereis excellent correlation between fatigue life and the area of the crack initiating particle. This is consistent with other studies that show good correlation between fatigue life and the area of the fatigue crack initiation defect. ${ }^{32,37}$ Furthermore, an example of a large fatal fatigue crack initiating particle $\left(\mathrm{Al}_{9} \mathrm{FeNi}\right)$ in this alloy (loaded as shown in Figure 6a) can be seen in Figure $6 \mathrm{~b}\left(\sim 3114 \mu \mathrm{m}^{2} ; \mathrm{L}_{\max } \sim 170 \mu \mathrm{m} ; \mathrm{N}_{\mathrm{f}}=561010\right.$ cycles $)$. Moreover, similar fatal fatigue crack initiating particles have been previously reported ${ }^{[9]}$ for this alloy (e.g., 3800 $\mu \mathrm{m}^{2} ; \mathrm{L}_{\max } \sim 210 \mu \mathrm{m} ; \mathrm{N}_{\mathrm{f}}=410975$ cycles $)$. The size of these particles is within the size range 
given in Figure $5 \mathrm{~b}$ for this alloy. A similar example for the HIPped Al0.7Si is also provided in Figure $6 \mathrm{c}$, which is reproduced with permission from Mbuya et al. ${ }^{[9]}$ The specimen was loaded at a maximum strain of $0.85 \%$ and failed from a large $\mathrm{Al}_{9} \mathrm{FeNi}$ particle $\left(49300 \mu \mathrm{m}^{2}\right.$; $\left.\mathrm{L}_{\max } \sim 262 \mu \mathrm{m}\right)$ after only 22402 cycles. It is clearly possible to conclude from these observations that the lower bound fatigue life of the S-N specimens $\left(\sim 6 \times 6 \mathrm{~mm}^{2}\right.$ in crosssection) is controlled by the largest particles within the highly stressed volume in the sample.
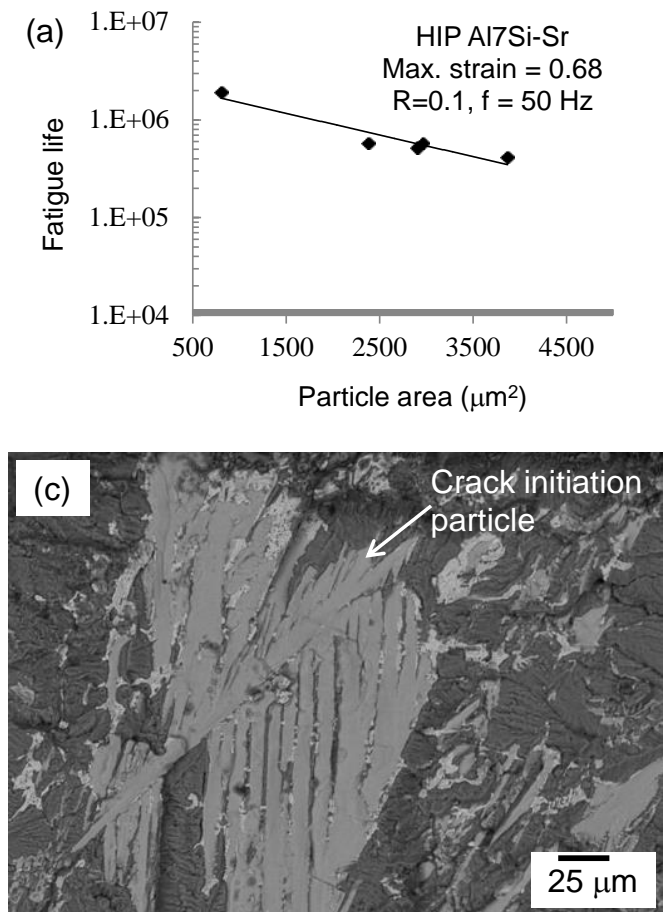
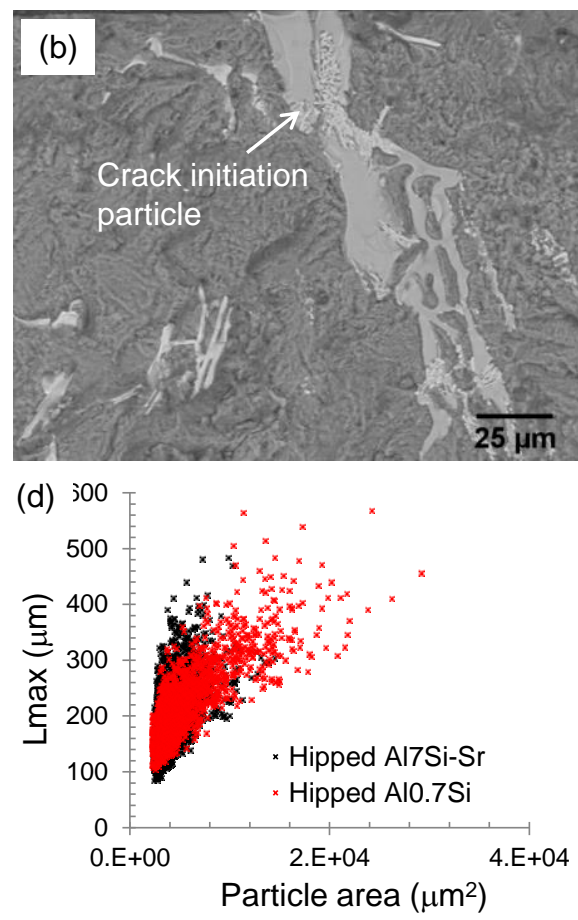

Figure 6. (a) Correlation between fatigue life and the size of fatal fatigue crack initiating particles for the HIPped A17Si-Sr alloy. (b) Exemplar fatigue crack initiating particle for the HIPped A17Si-Sr alloy and (c) Another exemplar fatigue crack initiating particle for the HIPped A10.7Si alloy. Figure 8c is reproduced with permission from Mbuya et al. ${ }^{[9]}$ (d) Maximum ferret length vs. areas of particles within the largest $0.1 \%$ of the population in all selected volumes of the HIPped A10.7Si and Al7Si-Sr alloys.

The S-N samples were loaded in 4 point bend such that the highly stressed top surface was $6 \times 10 \mathrm{~mm}^{2}$. The loading geometry inevitably limits the highly stressed volume to that nearest the surface and particle cracking would mostly be restricted to this region. A first estimate of the volume where particle cracking is expected to be confined can be achieved by applying the observation by Laz and Hillberry ${ }^{[38]}$ that crack initiation at particles (mainly $\mathrm{Al}_{7} \mathrm{Cu}_{2} \mathrm{Fe}$ ) in notched 2024-T3 specimens occurred at the regions where the stress was within $293 \%$ of the maximum. For the S-N specimens tested in the current study at stresses below the $0.2 \%$ proof stress, this region would be limited to a small layer from the top surface. However, most of the tests were carried out at maximum surface stresses which were above the $0.2 \%$ proof stress of the material. Finite element calculations indicated that for the most severe loading cases (i.e., $192 \mathrm{MPa}$ for $\mathrm{Al} 0.7 \mathrm{Si}$ and $143 \mathrm{MPa}$ for $\mathrm{Al} 7 \mathrm{Si}-\mathrm{Sr}$ ); the regions where the stresses were above $93 \%$ of the maximum were up to $\sim 0.64 \mathrm{~mm}$ deep for A10.7Si and $\sim 0.51 \mathrm{~mm}$ for Al7Si-Sr. It was also found that the regions experiencing stresses above the $0.2 \%$ proof stress for these severe loading cases were up to $2.32 \mathrm{~mm}$ and $1.67 \mathrm{~mm}$ from the top surface for Al0.7Si and Al7Si-Sr, respectively. However, if we use $\sim 0.64 \mathrm{~mm}$ as a first estimate for both alloys, fatigue cracking will therefore be assumed to be limited to a volume (V) of less than $48 \mathrm{~mm}^{3}$ (i.e., $6 \times 10 \times 0.64 \mathrm{~mm}^{3}$ ). 
With the information now available, it possible to estimate the size of the largest particle expected in the highly stressed volume and therefore likely to control the lower bound fatigue life of the HIPped Al0.7Si alloy. This can be achieved as illustrated in Wang and Jones ${ }^{[32]}$ by using the parameters $\lambda_{\mathrm{g}}$ and $\delta$ estimated from the largest particle size data as shown in Figure 5a. More details on extreme value analysis found in refs. ${ }^{[34,39]}$ In summary, the maximum particle size to be predicted depends on the volume of the material for which the prediction is required which is accounted for by the return period, $T\left(\mathrm{~V} / \mathrm{V}_{\mathrm{o}}\right)$ which accounts for the volume sampled $\left(\mathrm{V}_{\mathrm{o}}\right)$ compared to the volume of the most stressed region of the $\mathrm{S}-\mathrm{N}$ specimens $(\mathrm{V})$. The volume effect can be extended to any given number of S-N specimens $(n)$ simply by multiplying $T$ with $n$. If we assume for the moment that $n=1$ (for one specimen), then EVA predicts the area of the largest particle in one S-N specimen of the HIPped A10.7Si as $3.33 \times 10^{4} \mu \mathrm{m}^{2}$ with a standard deviation (STD) of $9.78 \times 10^{3} \mu \mathrm{m}^{2}$ (see results in Table 3 ). This is consistent with the size range of fatigue crack initiating particles observed for this alloy as illustrated in the previous discussion (e.g. in Figure 6c). A similar analysis can be carried out for the HIPped A17Si-Sr alloy giving equivalent values of $1.57 \times 10^{4} \mu \mathrm{m}^{2}$ with STD of $2.78 \times 10^{3} \mu \mathrm{m}^{2}$ as shown in Table 3 . Moreover, assuming that particles may fail anywhere within the plastic region and taking the most severe case of a plastic layer of $2.32 \mathrm{~mm}$ deep from the surface, the predicted area of the largest particle in the A10.7Si case would be $3.79 \times 10^{4} \mu \mathrm{m}^{2}$ with STD of $1.15 \times 10^{4} \mu \mathrm{m}^{2}$. This is still within the crack initiating particle size range for this alloy.

Figure $5 \mathrm{~b}$ shows that particles with areas greater than $\sim 2000 \mu \mathrm{m}^{3}$ constitute a very small fraction of the particle population. We can take for example the largest $0.1 \%$ of the particle populations from each of the sample volumes used for EVA and plot their maximum Feret dimension $\left(\mathrm{L}_{\max }\right)$ against their areas as shown in Figure $6 \mathrm{~d}$. We note from the figure that the minimum $\mathrm{L}_{\max }$ is $\sim 100 \mu \mathrm{m}$ and $\sim 80 \mu \mathrm{m}$ for the HIPped Al0.7Si and Al7Si-Sr, respectively. Again we note by comparing with Figure 6 a that most of the fatigue crack initiating particles come from the upper tail of the population as discussed further in Mbuya et al. ${ }^{[9]}$

Table 3 Extreme value predictions of the largest particle sizes (areas) expected in the most stressed region of the S-N specimens for the HIPped A10.7Si and Al7Si-Sr alloys.

\begin{tabular}{llllll}
\hline & $\lambda_{\mathrm{g}} \mu \mathrm{m}^{2}$ & $\delta \mu \mathrm{m}^{2}$ & $\mathrm{~T}$ & $x(\mathrm{~T}) \mu \mathrm{m}^{2}$ & $\mathrm{SD}(x(\mathrm{~T})) \mu \mathrm{m}^{2}$ \\
\hline HIPped A10.7Si & 9666 & 3597 & 719 & 33323 & 9779 \\
HIPped A17Si-Sr & 7213 & 1675 & 161 & 15718 & 2782 \\
\hline
\end{tabular}

\subsection{Porosity Characteristics}

Figure 7 shows low magnification SRCT images of porosity in the unHIPped and HIPped Al0.7Si alloy. The percent volume fraction of porosity in the SRCT volumes is also indicated in the images as $\sim 0.26 \%$ in the unHIPped alloy, which is significantly reduced to $\sim 0.03 \%$ in the HIPped alloy. Porosity in the unHIPped alloy shows a complex morphology typical of shrinkage related porosity. ${ }^{[40]}$ The extent of one such pore is illustrated in Figure 7a (in red). Conversely, porosity in the HIPped alloy is smaller and less complex in shape. However, there is low level clustering of pores, indicating possible shrinkage pores that were broken down during the healing process and thus isolating the branched arms of the pores into isolated pores of reduced size.

The pore size and shape (sphericity) distributions of the unHIPped and HIPped alloys are presented in Figure $7 \mathrm{c}$ and $7 \mathrm{~d}$. The pore size data is presented in two measures, $L_{\max }$ and $D_{\text {eq }}$. These have previously been adopted ${ }^{[32]}$ as measures of pore size but they are not equivalent 
especially for pores with complex morphology. Figures 7c and d indicate a significant reduction in pore size and number density in the alloy after HIPping. They also indicate that HIPping increases the sphericity of pores as expected from the SRCT images in Figure 7a and $7 \mathrm{~b}$ in which pores in the HIPped alloy appear less complex in shape. Moreover, a significant drop in sphericity with increase in pore size is also observed in the unHIPped alloy.
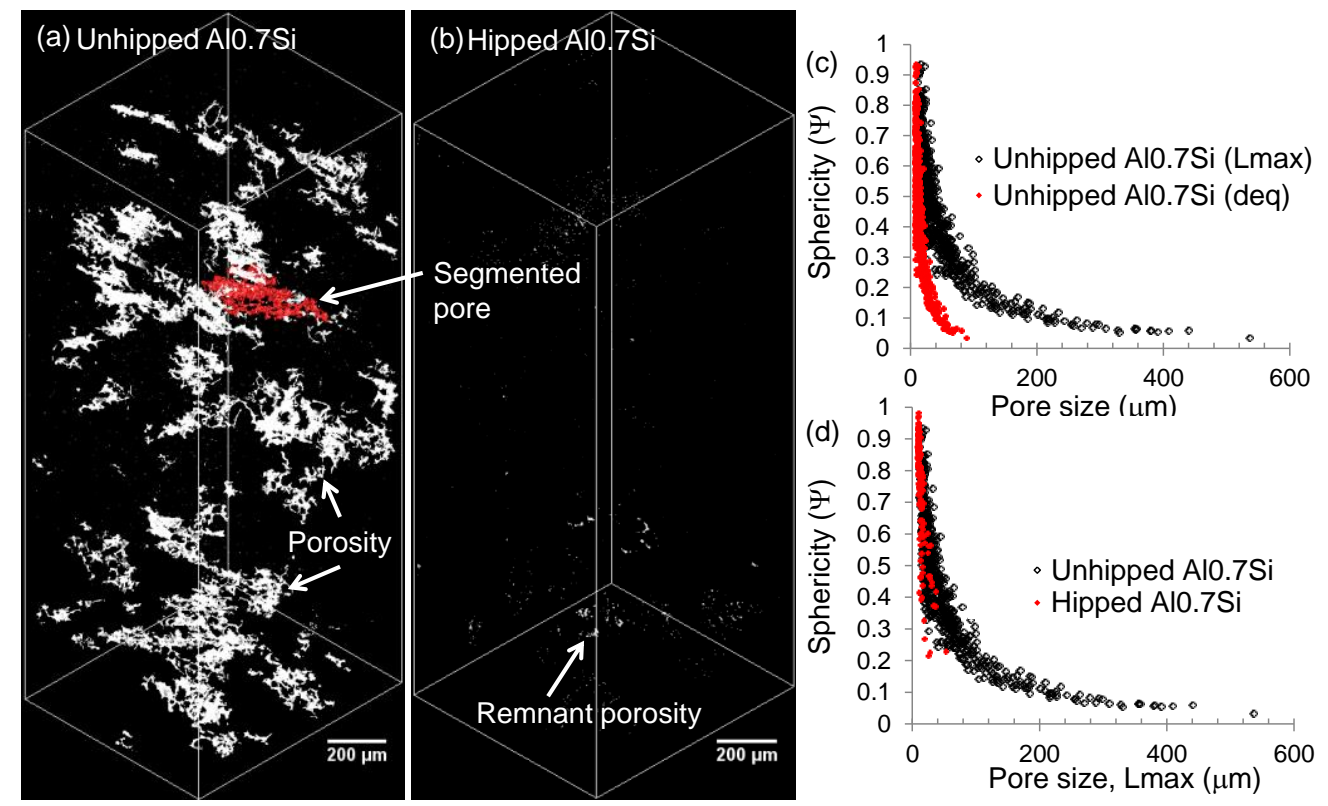

Figure 7. (a) and (b) 3D SRCT images showing the distribution of porosity in the non-HIPped and HIPped alloy. (c) and (d) show the effect of HIPping on pore size and shape distribution.

Figure 8a shows a high magnification SRCT image (video animation in the web version) of porosity around the large segmented pore illustrated in Figure 7a. The segmented pore is in red while the rest of the pores within this region $\left(302.4 \times 379.4 \times 274.4 \mu \mathrm{m}^{3}\right.$ in size $)$ are in white. The segmented pore clearly confirms the extensive nature of shrinkage porosity in the unHIPped alloy. It is apparent that pores in the unHIPped alloy extend across several dendrite arms and have significantly small cross sections (or thickness). It therefore appears that although the volume fraction of porosity may be small, this may not be the case with their area coverage. A single pore network can cover an extensive area over several dendrite arms and yet its volume is comparatively small. For example, the maximum dimension of this segmented pore is $\sim 458 \mu \mathrm{m}$. With an SDAS of $\sim 38 \mu \mathrm{m}$, this pore therefore spans across several dendrite arms as observed in the image, while its thickness is $\sim 2$ to $4 \mu \mathrm{m}$. A $2 \mathrm{D}$ slice through any section of this pore will reveal only several small pores clustered together. This is illustrated in Figure 8b, which shows an SRCT slice that intersects the pore within the volume. A video animation through all the slices within this SRCT volume is provided in the web version of this article. It is also instructive to observe the close association of the pores with intermetallics in the SRCT slices. The maximum Feret dimension of the largest pore observed in these $2 \mathrm{D}$ slices is $\sim 189 \mu \mathrm{m}$. Figures $8 \mathrm{c}$ and $8 \mathrm{~d}$ on the other hand show small clustered pores of fairly regular morphology in the HIPped alloy found in an equivalent set of high magnification SRCT images (video animations in the web version). It can be seen in the images (or animations) that the cluster of pores possibly consisted of a single complex-shaped pore that was broken down to isolated pores during HIPping. The SRCT slice animation of the HIPped alloy in Figure 8d also shows remnants of porosity along dendrite boundaries that did not completely heal during HIPping. This could be attributed to the presence of oxide films associated with pores which prevent complete welding of the pore during HIPping. ${ }^{[26]}$ 

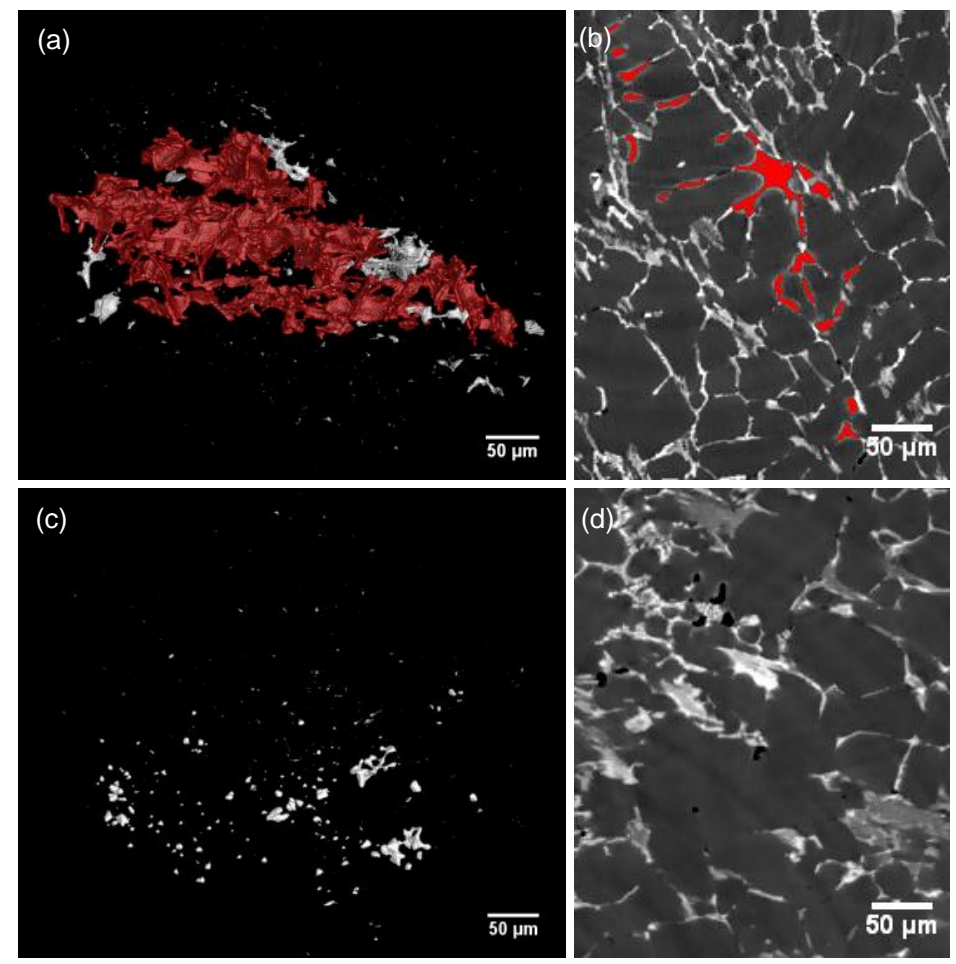

Figure 8. (a) 3D SRCT image (video animation in the web version) of a large shrinkage pore (red) in the non-HIPped alloy and (b) a 2D SRCT slice through the pore (video animation of the SRCT slices through the volume in the web version). (c) and (d) Equivalent SRCT images (video animations in the web version) of porosity in the HIPped alloy.

The pore size and shape distribution of the unHIPped and HIPped Al7Si-Sr alloy is shown in Figure 9a. It is evident that the large pores observed in the unHIPped alloy are drastically reduced in the HIPped alloy. It is similarly observed that large pores have complex morphology as evidenced by their low sphericity values. Figures $9 \mathrm{~b}$ and $9 \mathrm{c}$ also show that exemplar fracture surface images of fatigue crack initiating pores in both $\mathrm{Al} 0.7 \mathrm{Si}$ and $\mathrm{Al} 7 \mathrm{Si}$ $\mathrm{Sr}$ in the unHIPped condition. Moffat ${ }^{[41]}$ has reported that porosity plays a dominant role on the fatigue performance of these alloys. However, fatigue crack initiating pores were often found to be associated with intermetallic particles as shown in Figure 9c. This synergistic effect of porosity and hard particles on fatigue performance has been noted in previous studies. ${ }^{[18,42]}$ This is expected because shrinkage porosity is interdendritic and therefore inevitably interacts with secondary particles ( $\mathrm{Si}$ and intermetallics) during microstructure evolution.

Finally, it instructive to note the significant difference between the two pore size measures of $\mathrm{L}_{\max }$ and $\mathrm{D}_{\mathrm{eq}}$ in Figure $7 \mathrm{c}$ and thus the question as to which of the two is the appropriate pore size parameter to be used in fatigue life prediction models. The square root of the pore area $(\sqrt{\text { area }})$ has previously been adopted as a suitable measure of the size of fatigue crack initiating pores on fracture surfaces and found to correlate well with fatigue life. ${ }^{[32]}$ This implies that the appropriate parameter may be the area of the pore as projected along the loading direction. The $\mathrm{L}_{\max }$ of the pore in Figure 8a may therefore overestimate its effect on fatigue performance due to its complexity. Depending on the orientation of this pore with respect to the loading direction, its effective area (in terms of crack initiation) is likely to be confined within a few dendrites for a typical mode I loading. On the other hand, $\mathrm{D}_{\mathrm{eq}}$ may underestimate the effective size of this pore due to its apparently small overall thickness, which implies a relatively small volume. 

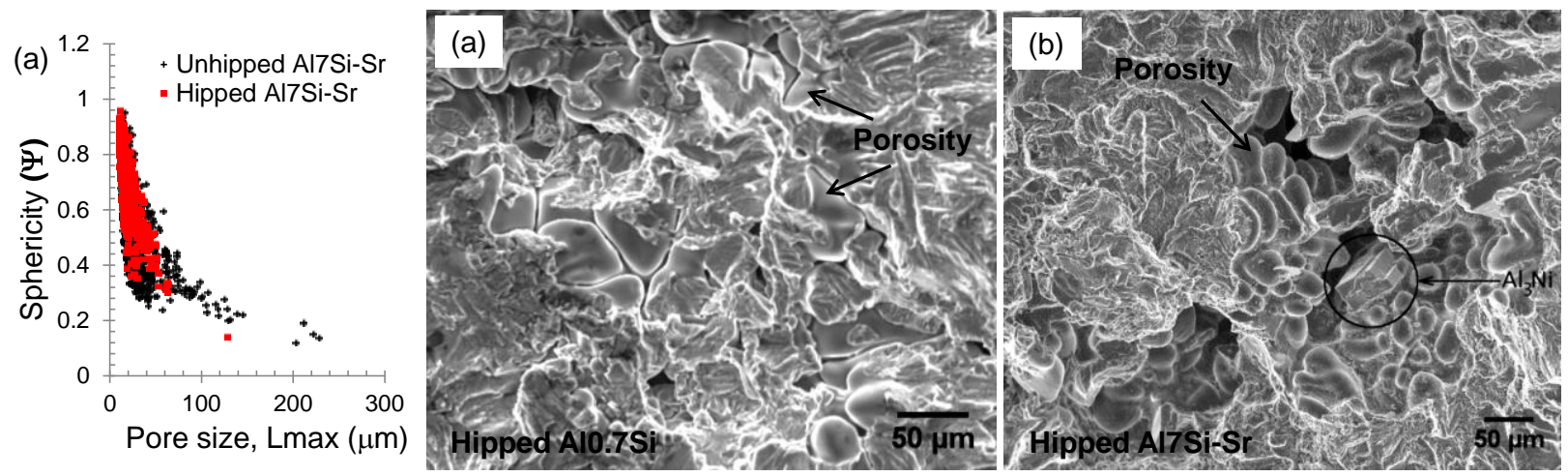

Figure 9. (a) Pore size and shape distribution of the unHIPped and HIPped Al7Si-Sr alloy. (b) and (c) SEM fracture surface images showing fatigue crack initiation from porosity in uHIPped A10.7Si and Al7Si-Sr alloys respectively. ${ }^{[41]}$

\subsection{Conclusions}

The 3D architecture of intermetallics and porosity distribution in two multicomponent cast $\mathrm{Al}-\mathrm{Si}-4 \mathrm{Cu}-3 \mathrm{Ni}-\mathrm{Mg}$ alloys (with $6.9 \% \mathrm{Si}$ and $0.7 \% \mathrm{Si}$ ) is characterised using conventional microscopy (optical/SEM) and synchrotron radiation computed tomography. These are then correlated to fatigue performance. The following conclusions can be drawn:

1. Both $\mathrm{Al}-7 \mathrm{Si}-4 \mathrm{Cu}-3 \mathrm{Ni}-\mathrm{Mg}$ and $\mathrm{Al}-0.7 \mathrm{Si}-4 \mathrm{Cu}-3 \mathrm{Ni}-\mathrm{Mg}$ alloys are found to contain intermetallic phases such as $\mathrm{Al}_{3} \mathrm{Ni}, \mathrm{Al}_{3}(\mathrm{NiCu})_{2}, \mathrm{Al}_{9} \mathrm{FeNi}$ and $\mathrm{Al}_{5} \mathrm{Cu}_{2} \mathrm{Mg}_{8} \mathrm{Si}_{6}$ that are generally interconnected into a complex $3 \mathrm{D}$ network.

2. HIPping slightly reduces the intermetallic volume fraction of the low Si alloy from $\sim 12.1 \pm 2.2 \%$ to $\sim 9.7 \pm 1.6 \mu \mathrm{m}$ possibly due to partial dissolution of $\mathrm{Al}_{5} \mathrm{Cu}_{2} \mathrm{Mg}_{8} \mathrm{Si}_{6}$ and $\mathrm{Al}_{2} \mathrm{Cu}$ phases during HIPping and solution treatment. Large intermetallic clusters are observed in both versions of this alloy. Crack-like oxides were also observed in the HIPped low Si alloy and attributed to pores co-existing with oxides that did not completely heal during HIPping.

3. HIPping does not affect the volume fraction of hard particles ( $\mathrm{Si}$ and intermetallics) in the high Si alloy which was found to be $19.5 \pm 2.4 \%$ for the unHIPped alloy and 19.4 $\pm 2.0 \%$ for HIPped alloy. The volume fraction of intermetallics alone was found to be $10.8 \pm 2.8 \%$, which is comparable to that of the low Si alloy.

4. HIPping does not significantly affect the size and shape distribution of the intermetallic phases in both alloys.

5. A novel technique similar to serial sectioning is proposed to quantify the intermetallic particles. The upper tail of the particle sizes is found to correlate well with particles that initiate fatal fatigue cracks.

6. The maximum particle size in a sample of S-N fatigue specimens predicted by extreme value analysis is shown to compare well with fatigue crack initiating particles and can therefore be used to predict the lower bound fatigue life in the given sample.

7. Large pore clusters with complex morphology are observed in the unHIPped versions of both alloys but more significant in the low Si alloy. HIPping significantly reduces the volume fraction, size and shape complexity of porosity in both low and high $\mathrm{Si}$ alloys. The significant difference between 2D and 3D pore morphology and size distribution is discussed in terms of the appropriate pore size parameter for fatigue life prediction. 


\section{References}

[1] B. Zhang, D.R. Poirier, W. Chen, Metall. Mater. Trans. A 1999, 30, 2659.

[2] Q.G. Wang, C.J. Davidson, J.R. Griffiths, P.N. Crepeau, Metall. Mater. Trans. B 2006, $37,887$.

[3] Q.G. Wang, D. Apelian, J.R. Griffiths, in: Advances in Aluminum Casting Technology (Eds: M. Tiyrakioglu, J. Campbell), October, 12-15, Rosemont, Illinois (USA) ASM International, 1998, 217-223.

[4] J.A. Taylor, Cast Metals 1995, 8, 225.

[5] Q.G. Wang, D. Apelian, D.A. Lados, J. Light Metals 2001, 1, 85-97.

[6] J.M. Boileau, J.E. Allison, J.W. Zindel, SAE Technical Paper Series 1997, No. 970019, 61-72.

[7] S.J. Mashl, J.C. Hebeisen, D. Apelian, Q. Wang, SAE Technical Paper Series 2000, No. 2000-01-0062.

[8] J.C. Hebeisen, B.M. Cox, SAE Technical Paper Series 2004, No. 2004-01-1027.

[9] T.O. Mbuya, I. Sinclair, A.J. Moffat, P.A.S. Reed, Mater. Sci. Eng. A 2011 528, 7331.

[10] Z. Asghar, G. Requena, E. Boller, Acta Mater. 2011, 59, 6420.

[11] A.J. Moffat, B.G. Mellor, C.L. Chen, R.C. Thomson, P.A.S. Reed, Mater. Sci. Forum 2006, 519-521, 1083.

[12] J.Z. Yi, Y.X. Gao, P.D. Lee, H.M. Flower, T.C. Lindley, Metall. Mater. Trans. A 2003, 34A, 1879.

[13] M.V. Kral, M.A. Mangan, G. Spanos, R.O. Rosenberg, Mater. Charact. 2000, 45, 17. [14] E.E. Underwood, Quantitative Stereology, Reading, MA, Addison-Wesley

Publishing Company, 1970.

[15] L. Salvo, P. Cloetens, E. Maire, S. Zabler, J. Blandin, J. Buffière, W. Ludwig, E.

Boller, D. Bellet, C. Josserond, Nucl. Instrum. Methods Phys. Res., B 2003, 200, 273.

[16] S.G. Lee, A.M. Gokhale, Scripta Mater. 2007, 56, 501.

[17] J.E. Spowart, Scripta Mater. 2006, 55, 5.

[18] J.Y. Buffiere, S. Savelli, P.H. Jouneau, E. Maire, R. Fougeres, Mater. Sci. Eng. A 2001, 316, 115.

[19] E. Maire, J.C. Grenier, D. Daniel, A. Baldacci, H. Klöcker, A. Bigot, Scripta Mater. 2006, 55, 123.

[20] W. Ludwig, J. Buffiere, S. Savelli, P. Cloetens, Acta Mater. 2003, 51, 585.

[21] A.J. Moffat, B.G. Mellor, I. Sinclair, P.A.S. Reed, Mater. Sci. Technol. 2007, 23, 1396.

[22] T.O. Mbuya, Y. Gu, R.C. Thomson, P.A.S Reed, Fatigue Fract. Eng. Mater. Struct. 2017, doi: $10.1111 /$ ffe.12586.

[23] M.M. Makhlouf, H.V. Guthy, J. Light Metals 2001, 1, 199.

[24] C.L. Chen, Characterisation of intermetallic phases in multicomponent Al-Si alloys for piston applications, PhD Thesis, IPTME, Loughborough University, 2006.

[25] R. Fuoco, E.R. Correa, L.S Escudo, AFS Trans. 1999, 107, 287.

[26] J.T. Staley Jr., M. Tiryakioglu, J. Campbell, Mater. Sci. Eng. A 2007, 460, 324.

[27] T.O. Mbuya, P.A.S Reed, Mater. Sci. Eng. A 2014, 612, 302.

[28] W.M. Edwards, R.C. Thomson, S.J. Barnes, S.I. Barnes, Mater. Sci. Forum 2002, 396-402, 625.

[29] C.H. Cáceres, J.A. Taylor, Metall. Mater. Trans. B 2006, 37(6), 897.

[30] J. Espinoza-Cuadra, P. Gallegos-Acevedo, H. Mancha-Molinar, A. Picado, Mater.

Design 2010, 31, 343.

[31] Y. Murakami, M. Endo, Int. J. Fatigue 1994, 16(3), 163.

[32] Q. Wang, P. Jones, Metall. Mater. Trans. B 2007, 38(4), 615. 
[33] K. Shiozawa, Y. Tohda, S.M. Sun, Fatigue Fract. Eng. Mater. Struct. 1997, 20(2), 237.

[34] A. Wormsen, B. Sjodin, G. Harkegard, A. Fjeldstad, Fatigue Fract. Eng. Mater. Struct. 2007, 30, 1214

[35] M. Tiryakioglu, Mater. Sci. Eng. A 2008, 497(1-2), 119.

[36] M. Tiryakioglu, Mater. Sci. Eng. A 2010, 527(6), 1560.

[37] M. Tiryakioğlu, Metall. Mater. Trans. A 2009, 40, 1623.

[38] P.J. Laz, B.M. Hillberry, Int. J. Fatigue 1998, 20(4), 263.

[39] T.O. Mbuya, Analysis of microstructure and fatigue micromechanisms in cast aluminium piston alloys, $\mathrm{PhD}$ Thesis, Faculty of Engineering and the Environment, University of Southampton, 2011. http://eprints.soton.ac.uk/348998/

[40] J.P. Anson, J.E. Gruzleski, Mater. Charact. 1999, 43, 319-335.

[41] Moffat, A.J. Micromechanistic analysis of fatigue in aluminium silicon casting alloys. PhD Thesis, School of Engineering Sciences, University of Southampton, 2007. http://eprints.soton.ac.uk/52400/

[42] Q.G. Wang, D. Apelian, D.A. Lados, J. Light Metals 2001, 1, 73. 


\section{ToC short text:}

Two cast $\mathrm{Al}-7(0.7) \mathrm{Si}-4 \mathrm{Cu}-3 \mathrm{Ni}-\mathrm{Mg}$ alloys contain a complex 3D network of intermetallics and large complex-shaped pores. HIPping reduces the volume fraction (Vf), size and shape complexity of pores, but no effect is observed for intermetallics except a slight reduction in the Vf of $0.7 \mathrm{wt} \% \mathrm{Si}$ alloy. A novel technique akin to serial sectioning is used to quantify intermetallics. The upper tail of particle sizes correlates well with fatigue crack initiating particles.

\section{Thomas O. Mbuya, * Ian Sinclair, Katherine A. Soady and Philippa A. S. Reed}

Application of X-Ray Microtomography to Evaluate Complex Microstructure and Predict the Lower Bound Fatigue Potential of Cast Al-7(0.7)Si-4Cu-3Ni-Mg Alloys

ToC Graphic:

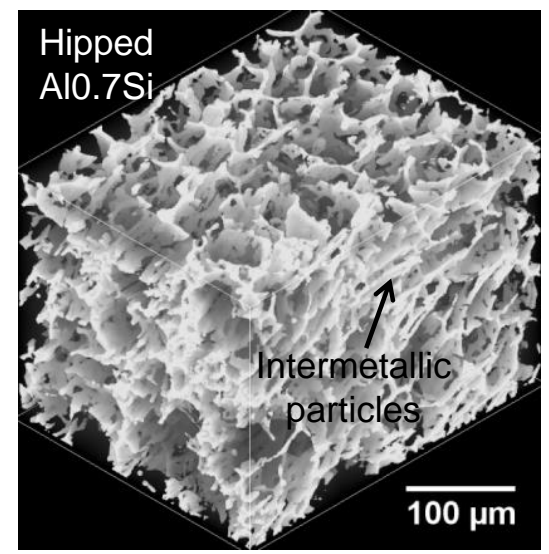

